\title{
SEPTICAEMIC MELIOIDOSIS IN A DIABETIC PATIENT FROM A TERTIARY CARE CENTRE IN KERALA
}

\author{
Netto Jacob ${ }^{1}$, Nimmy Paul2 2 Shoba Kurian Pulikottil33, Sreekumary P. $K^{4}$
}

${ }^{1}$ Senior Resident, Department of Microbiology, Government Medical College, Kottayam, Kerala, India. ${ }^{2}$ Assistant Professor, Department of Microbiology, Government Medical College, Kottayam, Kerala, India. 3 Professor, Department of Microbiology, Government Medical College, Kottayam, Kerala, India. ${ }^{4}$ Associate Professor, Department of Microbiology, Government Medical College, Kottayam, Kerala, India.

HOW TO CITE THIS ARTICLE: Jacob N, Paul N, Pulikottil SK, et al. Septicaemic melioidosis in a diabetic patient from a tertiary care centre in Kerala. J. Evolution Med. Dent. Sci. 2018;7(43):4695-4696, DOI: 10.14260/jemds/2018/1047

\section{PRESENTATION OF CASE}

A 62-year-old male presented to the Medicine Department with altered sensorium with a history of fever of unknown origin of 6 weeks duration. Initially, it was low-grade, on and off fever, which later got converted into high-grade fever with chills and rigors. No h/o cough, dysuria, loose stools, vomiting or headache. No h/o any surgeries in the past, bathing in open water bodies or wound which came in contact with soil (as the patient remembers of). He was a known case of diabetes and was on oral hypoglycaemics. He consulted a doctor in a local hospital and was started on oral amoxicillin and later referred to our hospital as he was not improving.

On examination, vitals were stable. He was febrile and pale. Abdominal examination revealed mild abdominal tenderness. The examinations of other systems were unremarkable.

\section{CLINICAL DIAGNOSIS}

Fever of Unknown Origin

\section{DIFFERENTIAL DIAGNOSES}

- Infective endocarditis.

- HIV infection.

- Brucellosis.

\section{PATHOLOGICAL DISCUSSION}

Laboratory examination revealed a total count of 12,000 , which later elevated to 14,000 . Blood sugar was $255 \mathrm{mg} / \mathrm{dL}$ with normal renal function. Peripheral smear reported as neutrophilic leucocytosis with toxic granules. CSF study was done and was normal. Later, an USG abdomen was done which revealed ill-defined hypoechoic lesion involving splenic parenchyma, largest measuring $2.1 \times 1.3 \mathrm{~cm}$. As the patient's condition was bad, abscesses were not drained. Blood sample was sent to microbiology laboratory for culture and sensitivity. Blood culture revealed B. pseudomallei.

'Financial or Other Competing Interest': None.

Submission 13-09-2018, Peer Review 08-10-2018,

Acceptance 15-10-2018, Published 22-10-2018.

Corresponding Author:

Dr. Netto Jacob,

Muthanattu (H), Poonjar P. O.,

Kottayam-686581,

Kerala, India.

E-mail: nettomuthanattu@gmail.com

DOI: $10.14260 / \mathrm{jemds} / 2018 / 1047$

\section{(c) (i) $(9)$}

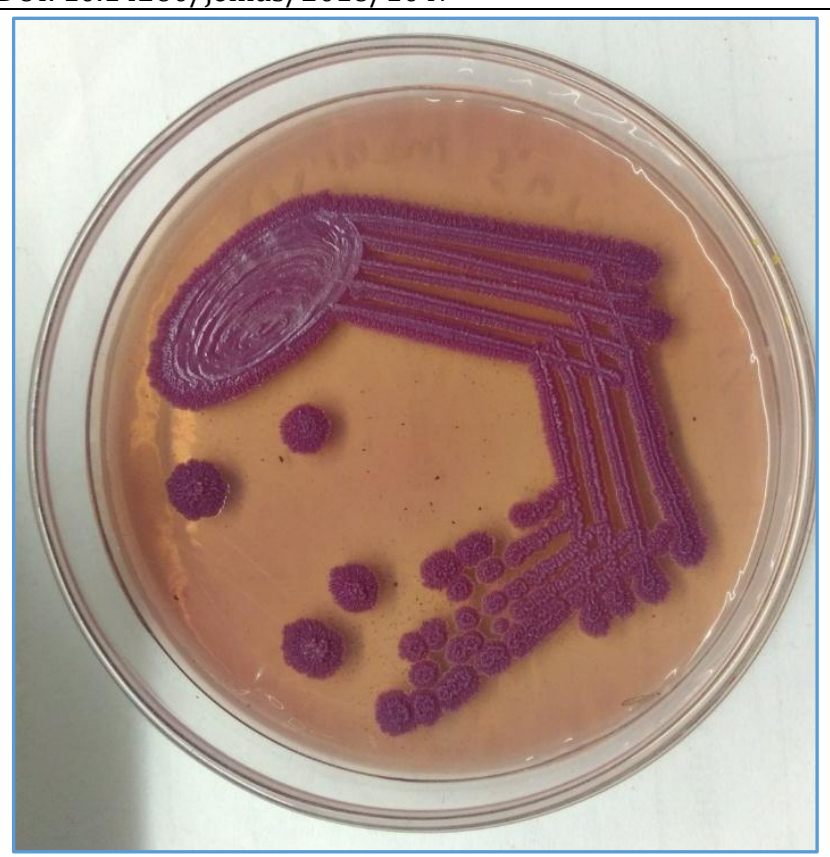

Figure 1. Colonies of B. pseudomallei on Ashdown's Medium

Burkholderia pseudomallei, the causative agent of melioidosis, is a gram-negative bacterium with rounded ends and bipolar staining, seen in tropical and subtropical soils and waters. It has got a high degree of virulence and strong antibiotic resistance.1,2 A number of risk factors for developing melioidosis such as diabetes, thalassaemia, renal disease and occupational exposure to surface water have been defined. Patients with diabetes mellitus, in particular, have a high incidence. ${ }^{3,4} \mathrm{~A}$ male preponderance is evident in all melioidosis case reports published. This likely reflects the outdoor work and occupational exposure to soil and water. The incidence is high during rainy seasons, as the bacteria move to the surface with rising water table and multiply in the surface water and wet soil.4 Pneumonia is the most frequent presentation of melioidosis and is involved in approximately half of all cases. ${ }^{1}$ But when presenting as acute septicaemic melioidosis, the mortality is high, at least $34 \%$ despite treatment with ceftazidime, the current treatment of choice. ${ }^{5}$ Isolation of $B$. pseudomallei from the body fluids of patients still remains the gold standard in the diagnosis. ${ }^{1}$

\section{DISCUSSION OF MANAGEMENT}

B. pseudomallei is frequently resistant to many antibiotics including aminoglycosides and first- or second-generation cephalosporins. ${ }^{6}$ Since other third-generation cephalosporins such as ceftriaxone are less active, ceftazidime is the treatment of choice.7,8 Current interventions are early intravenous administration of antibiotics, ceftazidime or 
carbapenems for 10 to 14 days followed by oral administration of cotrimoxazole or cotrimoxazoledoxycycline for 12 to 20 weeks. $^{2}$

In this case, the patient might have been infected as a result of occupational exposure, a minor trauma which went unnoticed or it could be an earlier exposure as the disease is notorious for latency and reactivation. The presence of diabetes mellitus as a risk factor is accountable for the development of septic shock. Early treatment is also essential in case of melioidosis. If the patient is in sepsis with abscesses in spleen or liver, if you have ruled out routine causes like infective endocarditis or HIV related abscesses, patient should be started on Ceftazidime ( $50 \mathrm{mg} / \mathrm{kg}$, upto $2 \mathrm{~g}$ ) every 6 hours or Meropenem (25 mg/kg, upto $1 \mathrm{~g}$ ) every 8 hours even before the isolation of organism in cultures.

Initially, patient was started on Inj. Ceftriaxone $2 \mathrm{~g}$ IV BD and Inj. Acyclovir $500 \mathrm{mg}$ IV Q8H. Blood culture sent to microbiology laboratory yielded Burkholderia pseudomallei sensitive to Ceftazidime, Meropenem, Doxycycline and Cotrimoxazole and resistant to Ciprofloxacin, Chloramphenicol and Amoxyclav. Based on antibiotic sensitivity, the antibiotic was changed to Inj. Meropenem $1 \mathrm{~g}$ IV Q8H. Patient responded well to intravenous Meropenem therapy and after 2 weeks of intravenous therapy, he was sent home on oral Doxycycline.

\section{FINAL DIAGNOSIS}

Septicaemic Melioidosis.

Septicaemic melioidosis is often a fatal disease despite treatment with antibiotics such as ceftazidime to which Burkholderia pseudomallei is sensitive in vitro. We report a case of B. pseudomallei causing sepsis in a diabetic patient. A 62-year-old diabetic farmer referred from a peripheral hospital with high-grade fever and altered sensorium. The patient was treated with meropenem and responded well to the treatment.

\section{REFERENCES}

[1] Redondo MC, Gómez M, Landaeta ME, et al. Melioidosis presenting as sepsis syndrome: a case report. Int J Infect Dis 2011;15(3):e217-8.

[2] Jin JL, Ning YX. Septicemic melioidosis: a case report and literature review. J Thorac Dis 2014;6(2):E1-4.

[3] Cheng AC, Currie BJ. Melioidosis: epidemiology, pathophysiology, and management. Clin Microbiol Rev 2005;18(2):383-416.

[4] Ramamoorthi K, Saravu K, Mukhyopadhyaya C, et al. Melioidosis: an underdiagnosed disease in India (epidemiology, clinical features, and outcomes). Asian Biomed 2013;7(2):249-56.

[5] Inglis TJ, Golledge CL, Clair A, et al. Case report: recovery from persistent septicemic melioidosis. Am J Trop Med Hyg 2001;65(1):76-82.

[6] Subbalaxmi MV, Chandra N, Rao MN, et al. Burkholderia pseudomallei: an uncommon cause of bacteraemic pneumonia in a diabetic. Indian J Chest Dis Allied Sci 2011;53(3):185-7.

[7] Dance DA. Melioidosis: the tip of the iceberg? Clin Microbiol Rev 1991;4(1):52-60.

[8] Lu PL, Tseng SH. Fatal septicemic melioidosis in a young military person possibly co-infected with Leptospira interrogans and Orientia tsutsugamushi. Kaohsiung J Med Sci 2005;21(4):173-8. 